УДК $314.335 .044 ; 316.346$

$10.17213 / 2075-2067-2021-2-92-103$

\title{
СОВРЕМЕННАЯ РОССИЙСКАЯ МОЛОДЕЖЬ: ЦЕННОСТНЫЕ АСПЕКТЫ РЕАЛИЗАЦИИ РЕПРОДУКТИВНЫХ НАМЕРЕНИЙ
}

\author{
(C) 2021 г. О. В. Кучмаева ${ }^{* * * *}$, О. А. Золотарева, С. Б. Гуляев* \\ "Институт демографических исследований \\ Федерального научно-исследовательского социологического центра РАН, \\ 2. Москва, Россия \\ *"Московский государственный университет \\ имени М. В. Ломоносова, г. Москва, Россия
}

Целью исследования является анализ репродуктивных ориентаџий молодежи и их детерминации. Статья основана на данных Всероссийского исследования "Демографическое самочувствие населения регионов России», проведенного в коние 2019 - начале 2020 г2.

Методы исследования. Для решения поставленных задач использованы методы статистического анализа данных выборочных обследований, методы дескриптивной статистики и метод многомерной классификации качественных переменных - построение дерева ицелей (для выявления иченностных факторов, определяющих желаемое число детей для лии в возрасте до 35 лет).

Результаты исследования показали, что репродуктивные намерения и оценка условий их реализации в значительной мере определяются ценностными ориентациями молодежи. Это важно учитыввать при разработке демографической политики, результативность которой, вероятно, будет выше при реализации мер, направленных не только на улучшение условий жизнедеятельности молодежи, молодых семей, но и на их ценностные ориентаичии, систему потребностей.

Перспективы исследования видятся в уточнении репродуктивных намерений различных сочиально-демографических групп молодежи.

Ключевые слова: молодежь; репродуктивные намерения; репродуктивное поведение; рождаемость молодежи; факторы рождаемости; демографическая политика.

\section{MODERN RUSSIAN YOUTH: REPRODUCTIVE INTENTIONS AND ASSESSMENT OF THE POSSIBILITIES OF THEIR IMPLEMENTATION}

\author{
(C) 2021 O. V. Kuchmaeva, ,**, O. A. Zolotareva*, S. B. Gulyaev*
}

\section{"Institute of Demographic Research of the Federal Research Sociological Center of the Russian Academy of Sciences, Moscow, Russia \\ ${ }^{* *}$ Lomonosov Moscow State University, Moscow, Russia}

The aim of the study is to analyze the reproductive orientations of young people and their determination. The article is based on the data of the study "Demographic well-being of the population of the regions of Russia», conducted in late 2019-early 2020.

Research methods. To solve these problems, we used methods of statistical analysis of sample survey data, methods of descriptive statistics, and the use of the method of multidimensional 
classification of qualitative variables - building a goal tree (to identify value factors that determine the desired number of children for people under the age of 35).

The results of the study showed that the reproductive intentions and the assessment of the conditions for their implementation are largely determined by the value orientations of young people. This is important to take into account when developing a demographic policy, the effectiveness of which is likely to be higher when implementing measures aimed not only at improving the living conditions of young people and young families, but also at their value orientations and the system of needs.

The prospects of the study are seen in clarifying the reproductive intentions of various sociodemographic groups of young people.

Key words: youth; reproductive intentions; reproductive behavior; youth fertility; fertility factors; demographic policy.

Введение. В условиях сложной демографической ситуации, во многом обусловленной снижением рождаемости, особую актуальность приобретает оценка уровня, перспектив и детерминант рождаемости молодых поколений. С середины 1990-х гг. в России наблюдается тенденция откладывания времени появления на свет первенца. Значительное распространение получила практика рождения ребенка вне официального брака в основных брачных возрастах [9]. Старение рождаемости, наблюдаемое в большинстве регионов России, выступает еще одним важным аспектом, обуславливающим актуальность предмета исследования.

В данной работе рассматриваются некоторые аспекты репродуктивного поведения российской молодежи в возрасте до 35 лет включительно на основе данных первой волны Всероссийского мониторинга «Демографическое самочувствие населения регионов России» ${ }^{1}$, проведенной исследовательским коллективом под руководством доктора социологических наук Т.К. Ростовской в конце 2019 — начале 2020 гг.

Основными задачами работы выступает анализ репродуктивных намерений молодежи, оценка помех к их реализации, а также сравнительный анализ репродуктивных намерений различных поколений россиян.
Источники и методы. Предметом исследования выступает по сути перспективное репродуктивное поведение, на формирование характеристик которого в значительной степени оказывают влияние действующие в обществе социальные нормы. В соответствии с теорией демографического перехода воздействие экономических параметров на уровень рождаемости и реализацию репродуктивных намерений происходит не напрямую, а определяется иерархией системы ценностей [13]. Данный подход является основным в ходе проведенной работы.

В статье используются данные Всероссийского социологического исследования «Демографическое самочувствие России», проведенного путем анкетного опроса в конце 2019 — начале 2020 гг. в десяти субъектах Российской Федерации: г. Москве, Республике Башкортостан, Республике Татарстан, Ставропольском крае, Вологодской, Волгоградской, Ивановской, Московской, Нижегородской и Свердловской областях. Общий объем выборочной совокупности составил 5616 человек, в состав выборочной совокупности вошли представители различных поколений в возрасте от 17 до 50 лет. Для решения задач данной работы была сформирована подвыборка - респонденты в возрасте от 17 до 35 лет, 3137 человек. Выделение данной группы определяется, с одной стороны, достаточно устоявшимися демографическими

1 Всероссийское социологическое исследование «Демографическое самочувствие России», проведенное в конце 2019 - начале 2020 гг. в Центральном, Северо-Западном, Приволжском, Уральском, Северо-Кавказском, Южном федеральных округах. $\mathrm{N}=5616$ представителей различных поколений в возрасте от 17 до 50 лет. Рук. д. соц. Н., профессор Т.К. Ростовская. 
и социально-политическими критериями (например, в сферу жилищной политики включены молодые семьи, где возраст супругов не превышает 35 лет). Кроме того, именно на эти возраста приходится наибольшая доля заключаемых браков и рождений. В этот жизненный период молодые люди, создав определенную социально-экономическую базу с учетом своего жизненного опыта, принимают решение о создании семьи либо делают выбор в сторону одиночества.

Результаты репрезентативны для России в целом и для включенных в выборочную совокупность регионов.

Для решения поставленных задач использованы методы статистического анализа данных выборочных обследований, методы дескриптивной статистики и использование метода многомерной классификации качественных переменных - построение дерева целей (для выявления факторов, определяющих желаемое число детей для лиц в возрасте до 35 лет).

В качестве основного индикатора репродуктивных намерений использован показатель ожидаемого числа детей.

Репродуктивные намерения молодежи как предмет научных исследований. Внимание исследователей разных стран привлекает проблема снижения рождаемости. Однако при этом рождаемость молодых поколений, реализация репродуктивных намерений и факторы, определяющие уровень рождаемости, не так часто выступают предметом анализа. Публикации, посвященные проблемам рождаемости молодежи, достаточно часто затрагивают такие проблемы, как распространенность чайлдфри, добровольной бездетности, а также вопросам рождаемости совсем молодых, несовершеннолетних, не состоящих в браке [14].

Современной российской молодежи присущи в целом довольно низкие репродуктивные установки на фоне показателей родительского поколения [2].

Исследования показывают, что формирование представлений о своей будущей семейной жизни и детях происходит в условиях возрастающей неопределенности [12].

Значительное место в исследовании факторов рождаемости, формирования и реали- зации репродуктивных установок занимает анализ системы ценностей [1].

Среди молодого поколения присутствуют различные модели, характеризующие отношение к семье и родительству: наряду с сознательным отказом от роли отца или матери, мешающей реализации профессионального потенциала и карьерных устремлений, присутствует и традиционно-ценностный вариант, когда материнство и отцовство воспринимаются как священное призвание, а также компромиссные варианты [6].

Объектом исследования репродуктивных намерений молодежи в российских исследованиях довольно часто выступает студенческая молодежь [10, 11].

Выбор данного объекта, видимо, обусловлен, с одной стороны, величиной данной социально-демографической группы, модель поведения которой в значительной степени характерна для российской молодежи в целом. С другой - относительной простотой сбора информации. Следует согласиться с Т.К. Ростовской, которая в авторском исследовании эмпирически подтвердила, что «... студенческая молодежь является главным субъектом общественного воспроизводства, так как именно в данной возрастной группе, в основном, сконцентрирован репродуктивный потенциал социума» [8, с. 74].

Большинство студентов планируют иметь детей, и более половины из них - двоих детей. Студенты (юноши и девушки) высоко оценивают возможности мужчин выполнять отцовскую роль. Среди юношей даже чаще выражена установка на детоцентризм, нежели среди девушек [4].

Анализ репродуктивных намерений студенческой молодежи, проведенный в 2008 г. в г. Москве, выявил, что ориентации на желаемое количество детей у девушек ниже, чем у юношей. На формирование установки на детность влияет количество братьев и сестер в их семье. Анализ факторов, влияющих на формирование репродуктивных установок, показал, что значительное влияние на показатель ожидаемого числа детей оказывает оценка состояния здоровья [5]. Однако наиболее значимым фактором, который может положительно повлиять уже на реализацию репродуктивных потребностей молодых семей, является отвечающее 
современным социальным эталонам качество жизни $[7,3]$.

Актуальной исследовательской задачей представляется исследование специфики репродуктивного поведения российской молодежи на основе представительного массива данных, репрезентирующих их различные социальные и территориальные группы. Это позволит получить сопоставимые оценки и применить методы многомерного анализа данных.

Ценностные факторы, определяющие группы молодежи по числу ожидаемых детей. С учетом различных представлений молодежи о семье и родительстве при анализе репродуктивных намерений молодежи значительный интерес представляет выделение групп респондентов с различными репродуктивными намерениями в зависимости от ценностных параметров, в частности, значимости тех или иных характеристик предпочтительной модели семьи. Решение данной задачи возможно с помощью построения классификационных деревьев.

При построении деревьев решений в качестве целевой использовалась переменная «Ожидаемое число детей». Классификация была проведена отдельно для совокупности мужчин и женщин в возрасте до 35 лет. Отметим, что в целом по совокупности опрошенных показатель ожидаемого числа детей составил для женщин 1,978 ребенка, мужчин - 1,929 ребенка.

В качестве предикторов были отобраны переменные, ответы респондентов на вопрос: «Чтобы семья считалась счастливой, важны следующие условия...» (варианты ответов представлены в таблице 1). Переменные носят ранговый характер - изменяются от 1 до 5, в зависимости от степени значимости для респондента той или иной характеристики. Это позволит выявить роль системы ценностей, включающей семейные и внесемейные ценности, в реализации репродуктивных намерений молодежи.

После проведенного анализа были выбраны модели, полученные с помощью метода CHAID.

Рассмотрим полученные результаты.

Наилучшим предиктором для целевой переменной «Ожидаемое число детей» по ответам женщин были признаны такие переменные, как «Наличие детей», «Взаимопонимание между супругами, общие интересы», «Наличие главы семьи», «Совместное проживание со старшим поколением», «Материальный достаток».

\section{Предикторы, выбранные для создания классификационных деревьев}

\begin{tabular}{|c|l|}
\hline Переменная & \multicolumn{1}{c|}{ Характеристика переменной } \\
\hline$x_{1}$ & Наличие детей \\
\hline$x_{2}$ & Взаимопонимание между детьми и родителями \\
\hline$x_{3}$ & Доверие между супругами \\
\hline$x_{4}$ & Взаимопонимание между супругами, общие интересы \\
\hline$x_{5}$ & Материальный достаток \\
\hline$x_{6}$ & $\begin{array}{l}\text { Наличие главы семьи, на которого все могут опереться, принимающего на } \\
\text { себя всю ответственность за других }\end{array}$ \\
\hline$x_{7}$ & $\begin{array}{l}\text { Отсутствие у мужа (жены) вредных привычек - злоупотребления алкого- } \\
\text { лем, наркотиками }\end{array}$ \\
\hline$x_{8}$ & Возможность для каждого члена семьи поступать так, как он хочет \\
\hline$x_{9}$ & Уважительное отношение, забота о старших членах семьи \\
\hline$x_{10}$ & Совместное проживание со старшим поколением \\
\hline$x_{11}$ & Раздельное проживание со старшим поколением \\
\hline$x_{12}$ & Хорошая сексуальная жизнь \\
\hline
\end{tabular}




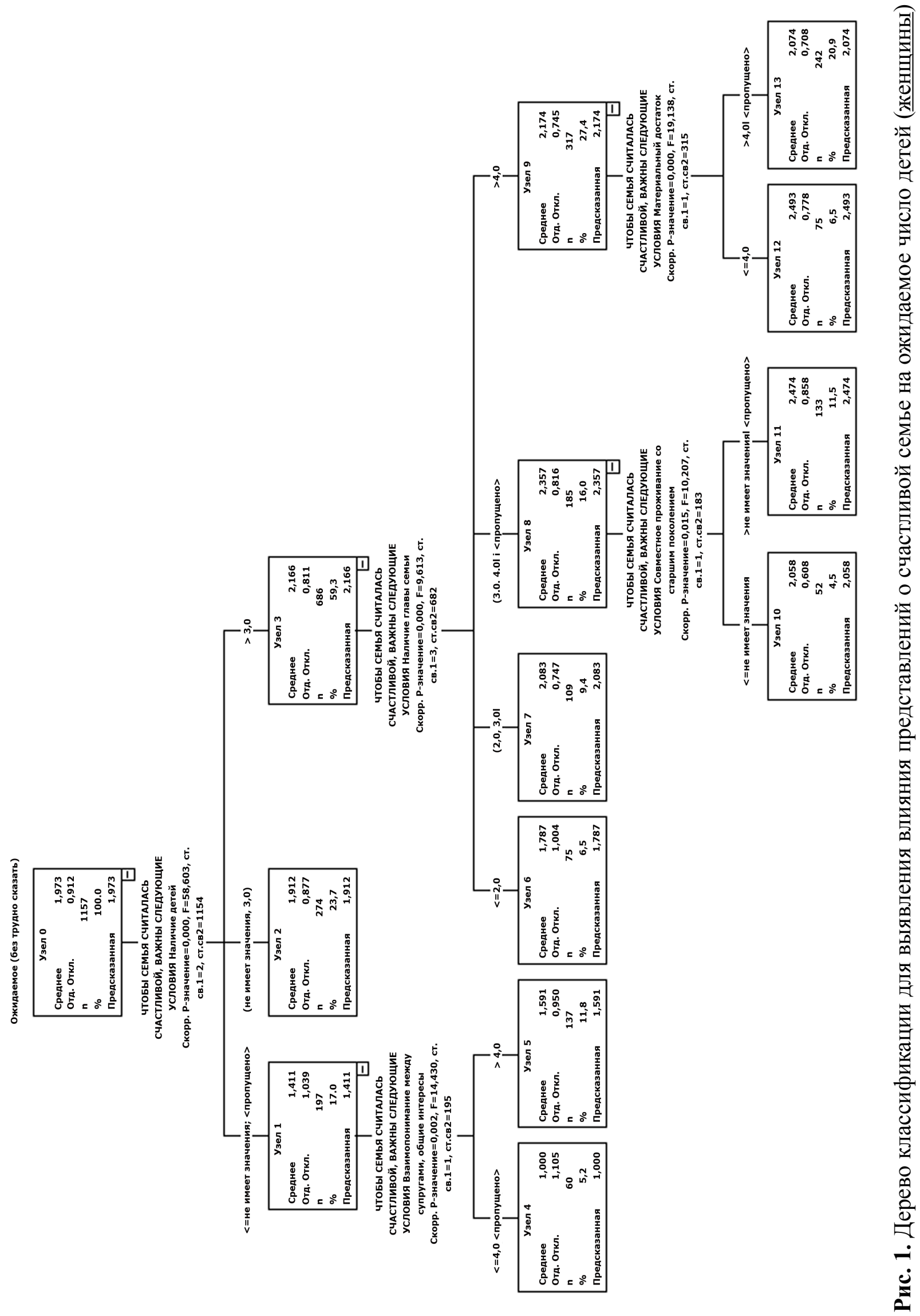


На рис. 1 представлено первое из построенных деревьев, которое является наилучшим среди построенных моделей для ответов женщин.

Корневой узел включает 1157 наблюдений - число женщин, давших ответы на вопросы и об ожидаемом числе детей, и о характеристиках счастливой, по их мнению, семьи.

О приемлемом качестве модели свидетельствует достаточно высокий процент респондентов, классифицированных верно. Так, согласно построенной модели, 76,6\% респондентов отнесены к одной из выделенных групп правильно.

В результате получено 9 терминальных узлов (групп респондентов). Различия в распределениях ответов респондентов значимы, проверка осуществлялась на основе критерия Хи-квадрат (значим на уровне не менее 0,015 ).

Основной фактор, влияющий на представление об ожидаемом числе детей для женщин, - значимость наличия детей в счастливой семье. В случае если молодые женщины согласны с этой точкой зрения и наличие детей для них весьма значимо (более 3 баллов по 5-балльной шкале), чтобы семью можно было назвать счастливой, показатель ожидаемого числа детей оставляет для них 2,166 и значительное влияние на величину ожидаемого числа детей оказывает также представление о необходимости главы в семье. Если значимость детей для счастья семьи низка, то показатель ожидаемого числа детей ниже $(1,917)$, и никакие другие факторы не оказывают на его величину значимого влияния.

Ряд респонденток уклонились от ответов на вопросы о характеристиках счастливой семьи либо выбрали вариант «затрудняюсь ответить» (197 человек). Однако для них показатели ожидаемого числа детей наиболее низкие $(1,411)$. Можно выделить и подгруппы в зависимости от значимости оценки взаимопонимания между супругами в браке. Представим краткое описание и наполненность полученных подгрупп.

1 группа - 274 женщины $(23,7 \%)$. Среднее ожидаемое число детей - 1,912 ребенка. Оценка значимости детей для счастья семьи - ниже 3 баллов по 5-балльной шкале.

2 группа - 60 женщин $(5,2 \%)$. Среднее ожидаемое число детей - 1,0 ребенка. Дети не имеют значения для счастья семьи, взаи- мопонимание между супругами в семейной жизни оценивается ниже, чем на 4 балла.

3 группа - 137 женщин $(11,8 \%)$. Среднее ожидаемое число детей - 1,591 ребенка. Дети не имеют значения для счастья семьи, однако взаимопонимание между супругами очень важно.

4 группа - 75 женщин (6,6\%). Среднее ожидаемое число детей - 1,787 ребенка. Дети очень важны для счастья семьи, однако традиционное распределение ролей, выделение главы семьи - неважно (оценка ниже 2 баллов).

5 группа - 100 женщин $(9,4 \%)$. Среднее ожидаемое число детей - 2,083 ребенка. Дети очень важны для счастья семьи, наличие главы в семье для семейного счастья оценивается не слишком высоко, на 2-3 балла.

В случае если женщина придерживается традиционных взглядов на распределение ролей в семье, для нее значимым условием семейного счастья выступает и совместное проживание со старшим поколением.

6 группа - 52 женщины (4,5\%). Среднее ожидаемое число детей - 2,058 ребенка. Дети очень важны для счастья семьи, наличие главы в семье для семейного счастья важно и оценивается на 3-4 балла. Однако совместное проживание со старшим поколением нежелательно (не имеет значения для счастья семьи).

7 группа - 133 женщины (11,6\%). Среднее ожидаемое число детей $-2,474$ ребенка. Дети очень важны для счастья семьи, наличие главы в семье для семейного счастья важно и оценивается 3-4 балла. Совместное проживание со старшим поколением имеет определенное значение для счастья семьи, оценка выше 1 балла.

Те женщины, для которых очень важно наличие главы в семье, различаются по оценке значимости материального положения для счастья семьи.

8 группа - 75 женщин (6,5\%). Среднее ожидаемое число детей - 2,493 ребенка (самый высокий показатель). Дети очень важны для счастья семьи, наличие главы в семье для семейного счастья очень важно (4 балла и выше). Материальный достаток оценивается на 4 балла и ниже.

9 группа - 242 женщин (20,9\%). Среднее ожидаемое число детей $-2,074$ ребен- 
ка. Дети очень важны для счастья семьи, наличие главы в семье для семейного счастья очень важно (4 балла и выше). Материальный достаток оценивается более чем на 4 балла.

К сожалению, наиболее типичной для современных молодых женщин выступает позиция не слишком высокой значимости детей как условия семейного счастья. Максимальные показатели ожидаемого числа детей наблюдаются среди женщин, придерживающихся традиционных взглядов: для счастья семьи необходимы дети, глава семьи, желательно проживание со старшим поколением, материальное благополучие. При этом среди женщин с традиционными взглядами показатель ожидаемого числа детей значимо ниже для тех, кто в большей степени ценит материальный достаток. Вместе с тем необходимо отметить, что наряду со значимостью детей как ценности счастливой семьи и брака, ориентации на традиционное распределение ролей в семье, определенное значение в увеличении показателя ожидаемого числа детей играет и нацеленность на взаимопонимание между супругами.

Для молодых мужчин итоговое дерево решений содержало 7 терминальных узлов (подгрупп). Предикторами, определяющими распределение мужчин на подгруппы в зависимости от показателя ожидаемого числа детей, выступили переменные: «Наличие детей», «Материальный достаток», «Доверие между супругами», «Взаимопонимание между детьми и родителями». Отметим, что для мужчин, в отличие от женщин, в перечень детерминант не вошли такие характеристики традиционной модели семьи, как совместное проживание со старшим поколением и наличие главы семьи. Однако на формирование подгрупп оказывают влияние такие характеристики, как взаимопонимание между детьми и родителями и доверие между супругами.

Корневой узел включает 1185 наблюдений, оценка риска составляет 17,7\% (82,3\% респондентов отнесены к одной из выделенных групп правильно).

Для молодых мужчин также ведущим фактором, влияющим на представление об ожидаемом числе, выступает «наличие детей» (для счастливой семейной жизни).

В случае если для молодых мужчин важно наличие детей как условие счастливой семьи, значимым фактором, определяющим различия в величине ожидаемого числа детей, выступает оценка материального достатка.

Каковы различия между типологическими группами мужчин?

1 группа - 233 мужчины (19,6\%). Среднее ожидаемое число детей - 1,373 ребенка. Дети как условие счастливой семейной жизни не имеют значения.

2 группа - 490 мужчин $(41,3 \%)$. Среднее ожидаемое число детей - 2,108 ребенка. Дети очень важны для счастья семьи (более 3 баллов), как и материальный достаток (более 3 баллов).

3 группа - 78 мужчин (6,6\%). Среднее ожидаемое число детей — 2,615 ребенка. Дети очень важны для счастья семьи (более 3 баллов), однако материальный достаток играет незначительную роль (менее 3 баллов).

Для мужчин, которые оценивают значимость детей как условие счастья семьи на среднем уровне (1-3 балла), на показатель ожидаемого числа детей оказывают влияние такие факторы, как материальный достаток, доверие между супругами, взаимопонимание между детьми и родителями.

4 группа - 61 мужчина $(5,1 \%)$. Среднее ожидаемое число детей - 2,344 ребенка. Дети важны для счастья семьи (1-3 балла), материальный достаток достаточно важен (менее 4 баллов), определенную роль играет доверие между супругами (менее 3 баллов).

5 группа - 170 мужчин (14,3\%). Среднее ожидаемое число детей - 1,965 ребенка. Дети важны для счастья семьи (1-3 балла), материальный достаток достаточно важен (менее 4 баллов), доверие между супругами очень важно (более 3 баллов).

6 группа - 74 мужчины (6,2\%). Среднее ожидаемое число детей - 1,365 ребенка. Дети важны для счастья семьи (1-3 балла), материальный достаток достаточно важен (менее 4 баллов), взаимопонимание между детьми и родителями играет определенную роль (менее 4 баллов).

7 группа - 80 мужчин (6,7\%). Среднее ожидаемое число детей - 1,912 ребенка. Дети важны для счастья семьи (1-3 балла), материальный достаток достаточно важен (менее 4 баллов), взаимопонимание между детьми и родителями играет большую роль (более 4 баллов). 


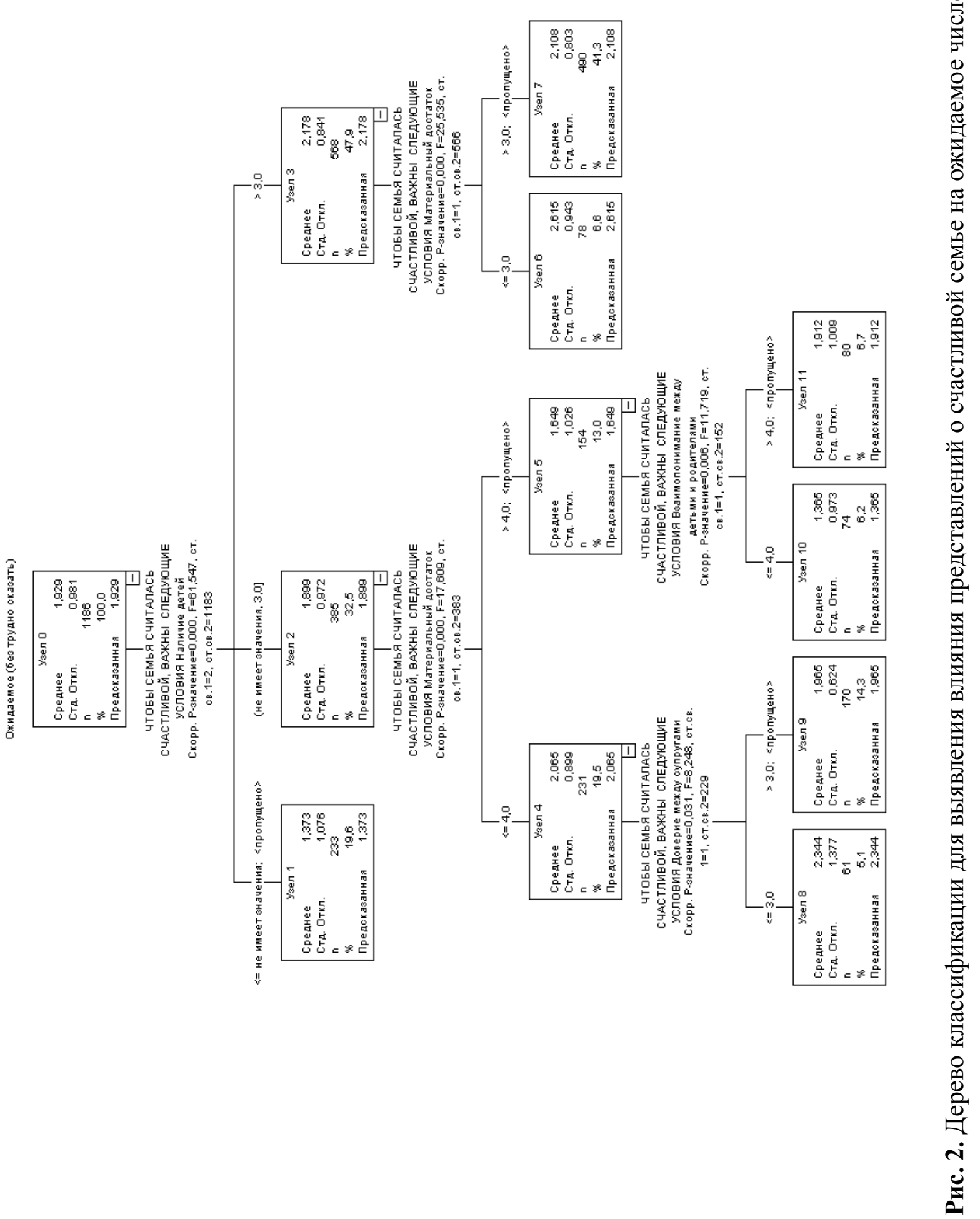


Хотя мужчины выступают меньшими приверженцами традиционного подхода к семейной жизни, тем не менее, можно выделить ряд общих черт в оценке параметров счастливой семьи и их влияния на репродуктивные установки. Для мужчин, считающих наличие детей условием семейного счастья, характерна более значительная величина ожидаемого числа детей, особенно для тех, кто в меньшей степени ценит материальный достаток. Среди мужчин, имеющих относительно более низкие репродуктивные установки, значимость доверительных отношений между супругами, родителями и детьми оказывает повышающее влияние на величину ожидаемого числа детей.

Выводы. Представленные результаты свидетельствуют о том, что соотношение значимости ценностей, во многом определяемая ими система потребностей зачастую являются значимым фактором, влияющим на восприятие тех или иных жизненных обстоятельств как мешающих или не мешающих иметь желаемое число детей.

Это обстоятельство, вероятно, нужно иметь в виду при разработке мер демографической политики, направленных на создание для молодежи более благоприятных условий реализации репродуктивных намерений. С одной стороны, влияние ценностных ориентаций будет, видимо, накладывать существенные ограничения на возможную результативность этих мер. С другой стороны, можно обоснованно предположить достижение большей результативности мер при направленности стратегии демографической политики как на улучшение условий жизнедеятельности молодежи, молодых семей, так и на их ценностные ориентации, систему потребностей.

Среди молодых людей, мужчин и женщин, можно выделить подгруппы, различающиеся по показателям, характеризующим их репродуктивные намерения, в частности, по величине ожидаемого числа детей. Ведущую роль играет место, которое занимают дети в системе ценностей. Среди женщин, в отличие от мужчин, можно выделить группу, в значительной степени ориентирующихся на традиционные ценности при создании семьи. Они отличаются более высокими показателями в контексте ожидаемого числа де- тей. Ценность материального достатка конкурирует с ценностью детей. Возможно, играет роль и тот факт, что в современной России понятие бедности в общественном сознании тесно увязано с бедностью семей с детьми.

Обращает на себя внимание тот факт, что в случае высокой значимости психологического комфорта в семье (для женщин взаимопонимание между супругами, для мужчин - доверие между супругами и взаимопонимание между детьми и родителями) показатель ожидаемого числа увеличивается.

Демографическая политика, направленная на повышение рождаемости, должна быть многовекторной, способствовать реализации репродуктивных намерений не только молодежи, придерживающейся взглядов на традиционную организацию семейной жизни, но и тех, для кого значима психологическая составляющая семейного счастья.

\section{Литература}

1. Антонов А.И., Карпова В.М., Ляликова С.В., Новоселова Е.Н., Синельников А.Б. Ценности семейно-детного образа жизни (СЕДОЖ-2019). Аналитический отчет по результатам межрегионального социолого-демографического исследования / Под редакцией А.И. Антонова. - М.: Макс Пресс, 2020. - C. 486.

2. Архангельский В. Н., Елизаров В.В., Зверева Н.В., Иванова Л.Ю. Демографическое поведение и его детерминация. - М.: Теис, 2005. - $352 \mathrm{c}$.

3. Архангельский В.Н., Ростовская Т.К., Васильева Е.Н. Влияние уровня жизни на репродуктивное поведение россиян: гендерный аспект // Женщина в российском обществе. - 2021. - №S. - C. 3-24.

4. Гурко Т.A. Представления студентов в отношении родительства и социальных ролей мужчин и женщин // Социологическая наука и социальная практика. - 2019. №2 (26). - С. 65-80.

5. Доброхлеб В.Г., Белобрагина Н. В. Репродуктивные ориентации студенческой молодежи// Вестник РГГУ. Серия: Экономика. Управление. Право. — 2010. — №6 (49). — С. 15-22.

6. Лескин Д.Ю. Семья как базовая ценность традиционного общества // Миссия конфессий. — 2016. — №26. - С. 9-16. 
7. Лещченко Я.А., Боева А.В. Качество жизни и репродуктивные установки молодых семей в Иркутской области // Проблемы социальной гигиены, здравоохранения и истории медицины. - 2019. - №4 (27). С. 429-433.

8. Ростовская T.K. Создание студенческой семьи: мотивация и жизненные стратегии членов молодых студенческих семей (итоги всероссийского межвузовского исследования)// Вестник Нижегородского университета им. Н.И. Лобачевского. Серия: Социальные науки. - 2015. - №4 (40). - С. 73-81.

9. Синявская О.В., Захаров С.В., Кариева М.A. Поведение женщин на рынке труда и деторождение в современной России. Родители и дети, мужчины и женщины в семье и обществе / под научн. ред. Т.М. Малевой, О.В. Синявской. - М.: НИСП, 2007. — 456 с.

10. Сурвилло Е. В. Сравнительный анализ репродуктивных установок студенток высших учебных заведений // Вестник новых медицинских технологий. - 2016. — №2. C. $152-155$.

11. Сучков А. Н. Репродуктивные установки в студенческой среде (по материалам социологического исследования) // Высшее образование в России. - 2014. - №10. - С. $44-49$.

12. Blossfeld P., Hofmeister H. Life courses in the globalization process. Final Report. Otto Friedrich University of Bamberg, 2005. [Electronic resource]. - URL: https://www. fachportal-paedagogik.de/literatur/vollanzeige. html? FId=757216\#vollanzeige (Date accessed: 10.03.2021).

13. Lesthaeghe R. Second Demographic Transition, Basil Blackwell. [Electronic resource]. - URL: http://www.vub.ac.be/SOCO/ ron/final textSDTBasilBlackwellEncyclop.doc (Date accessed: 10.03.2021).

14. Singh S., Darroch J. E. Adolescent Pregnancy and Childbearing: Levels and Trends in Developed Countries // Journal of Adolescent Health. - 2015. — №56 (2). — Pp. 223-230.

\section{References}

1. Antonov A.I., Karpova V.M., Ljalikova S.V., Novoselova E.N., Sinel'nikov A.B. Cennosti semejno-detnogo obraza zhizni (SEDOZh-2019). Analiticheskij otchet po rezul'tatam mezhregional'nogo sociologo-demografichesko- go issledovanija [The values of family and child lifestyle (SEDOZH-2019). Analytical report on the results of the interregional socio-demographic study] / In A. I. Antonov (eds.). — Moscow: Maks Press, 2020. - Pp. 486.

2. Arhangel'skij V. N., Elizarov V.V., Zvereva N. V., Ivanova L. Ju. Demograficheskoe povedenie i ego determinacija [Demographic behavior and its determination]. - Moscow: Teis, 2005. - $352 \mathrm{p}$.

3. Arhangel'skij V. N., Rostovskaja T.K., Vasil'eva E.N. Vlijanie urovnja zhizni na reproduktivnoe povedenie rossijan: gendernyj aspekt [Influence of the standard of living on the reproductive behavior of Russians: gender aspect] // Zhenshhina v rossijskom obshhestve [A woman in Russian society]. — 2021. — NoS. Pp. 3-24.

4. Gurko T.A. Predstavlenija studentov v otnoshenii roditel'stva i social'nyh rolej muzhchin i zhenshhin [Students ' views on parenthood and social roles of men and women] // Sociologicheskaja nauka i social'naja praktika [Sociological science and social practice]. — 2019. №2 (26). - Pp. 65-80.

5. Dobrohleb V.G., Belobragina N.V. Reproduktivnye orientacii studencheskoj molodezhi [Reproductive orientations of student youth] // Vestnik RGGU. Serija: Jekonomika. Upravlenie. Pravo [Series: Economics. Management. Law]. — 2010. — №6 (49). — Pp. 15-22.

6. Leskin D. Ju. Sem'ja kak bazovaja cennost' tradicionnogo obshhestva [Family as the basic value of traditional society] // Missija konfessij [The mission of the confessions]. 2016. — №26. 一 Pp. 9-16.

7. Leshhenko Ja. A., Boeva A.V. Kachestvo zhizni i reproduktivnye ustanovki molodyh semej v Irkutskoj oblasti [Quality of life and reproductive attitudes of young families in the Irkutsk region] // Problemy social'noj gigieny, zdravoohranenija $\mathrm{i}$ istorii mediciny [Problems of social hygiene, health care and the history of medicine]. - 2019. — №4 (27). — Pp. 429-433.

8. Rostovskaja T.K. Sozdanie studencheskoj sem'i: motivacija i zhiznennye strategii chlenov molodyh studencheskih semej (itogi vserossijskogo mezhvuzovskogo issledovanija) [Creating a student family: motivation and life strategies of members of young student families (results of the All-Russian interuniversity research)] // Vestnik Nizhegorodskogo universiteta im. 
N.I. Lobachevskogo. Serija: Social'nye nauki [Vestnik Nizhegorodskogo universiteta named after N.I. Lobachevsky. Series: Social Sciences]. - 2015. - №4 (40). - Pp. 73-81.

9. Sinjavskaja O.V., Zaharov S. V., Karceva M.A. Povedenie zhenshhin na rynke truda $\mathrm{i}$ detorozhdenie $\mathrm{v}$ sovremennoj Rossii. Roditeli i deti, muzhchiny i zhenshhiny $v$ sem'e i obshestve [The behavior of women in the labor market and childbearing in modern Russia. Parents and children, men and women in the family and society] / in T. M. Maleva, O. V. Sinjavskaya (eds.). - Moscow: NISP, 2007. — 456 p.

10. Survillo E.V. Sravnitel'nyj analiz reproduktivnyh ustanovok studentok vysshih uchebnyh zavedenij [Comparative analysis of reproductive attitudes of female students of higher educational institutions] // Vestnik novyh medicinskih tehnologij [Bulletin of new medical technologies]. — 2016. — №2. — Pp. 152-155.

11. Suchkov A. N. Reproduktivnye ustanovki $\mathrm{v}$ studencheskoj srede (po materialam socio- logicheskogo issledovanija) [Reproductive attitudes in the student environment (based on the materials of a sociological study)] // Vysshee obrazovanie v Rossii [Higher education in Russia]. — 2014. — №10. — Pp. 44- 49.

12. Blossfeld P., Hofmeister H. Life courses in the globalization process. Final Report. Otto Friedrich University of Bamberg, 2005. [Electronic resource]. - URL: https://www. fachportal-paedagogik.de/literatur/vollanzeige. html? FId=757216\#vollanzeige (Date accessed: 10.03.2021).

13. Lesthaeghe R. Second Demographic Transition, Basil Blackwell. [Electronic resource]. — URL: http://www.vub.ac.be/SOCO/ ron/final_textSDTBasilBlackwellEncyclop.doc (Date accessed: 10.03.2021).

14. Singh S., Darroch J. E. Adolescent Pregnancy and Childbearing: Levels and Trends in Developed Countries // Journal of Adolescent Health. - 2015. — №56 (2). — Pp. 223-230.

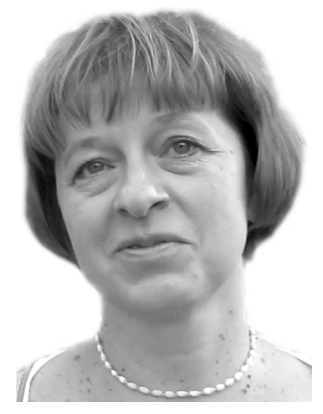

Кучмаева Оксана Викторовна - доктор экономических наук, главный научный сотрудник отдела Семьи и семейно-демографической политики Института демографических исследований Федерального научно-исследовательского социологического центра РАН; профессор кафедры народонаселения Московского государственного университета имени М. В. Ломоносова.

Kuchmaeva Oksana Viktorovna - Doctor of Economic Sciences, Chief Researcher of the Department of Family and FamilyDemographic Policy of the Institute of Demographic Research of the Federal Research Sociological Center of the Russian Academy of Sciences; Professor of the Department of Population of the Lomonosov Moscow State University.

121552, г. Москва, ул. Ярцевская, 33-1-37

33-1-37 Yartsevskaya st., 121552, Moscow, Russia

E-mail:kuchmaeva@yandex.ru 


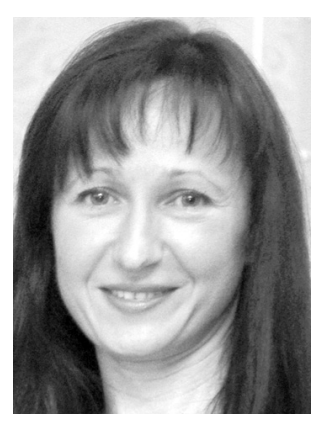

Золотарева Ольга Анатольевна - кандидат экономических наук, доцент, ведущий научный сотрудник отдела Семьи и семейно-демографической политики Института демографических исследований Федерального научно-исследовательского социологического центра РАН.

Zolotareva Olga Anatolyevna - Candidate of Economic Sciences, Associate Professor, Leading Researcher of the Department of Family and Family-Demographic Policy of the Institute of Demographic Research of the Federal Research Sociological Center of the Russian Academy of Sciences.

121471, г. Москва, Можайское шоссе, 15-7

15-7 Mozhaiskoe road, 121471, Moscow, Russia

E-mail: OAMahova@yandex.ru

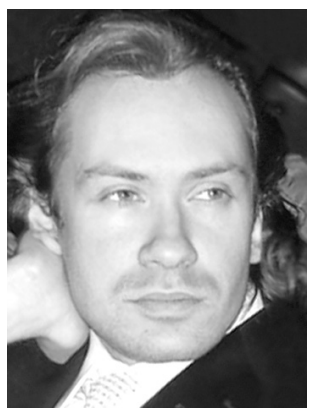

Гуляев Святослав Борисович - кандидат социологических наук, старший научный сотрудник отдела Семьи и семейнодемографической политики Института демографических исследований Федерального научно-исследовательского социологического центра РАН.

Gulyaev Svyatoslav Borisovich - Candidate of Sociological Sciences, Senior Researcher of the Department of Family and Family-Demographic Policy of the Institute of Demographic Research of the Federal Research Sociological Center of the Russian Academy of Sciences.

19333, г. Москва, ул. Фотиевой, 6, стр. 1 6 Fotievoj st., bld. 1, 119333, Moscow, Russia

E-mail: sviatoslav2004@mail.ru 